\title{
Structural stability of calcium phosphate cement during aging in water
}

\author{
Hsiu-Ching Hsu ${ }^{a}$, Chin-Yi Chiu ${ }^{a}$, Wei-Hsing Tuan ${ }^{a, *}$, Hsin-Yi Lee ${ }^{b}$ \\ ${ }^{a}$ Department of Materials Science and Engineering, National Taiwan University, Taipei 106, Taiwan \\ ${ }^{\mathrm{b}}$ National Synchrotron Radiation Research Center, Hsinchu 300, Taiwan
}

Available online 11 April 2007

\begin{abstract}
A calcium phosphate cement $(\mathrm{CPC})$ has been prepared by mixing dicalcium phosphate anhydrate $\left(\mathrm{DCPA}, \mathrm{CaHPO}_{4}\right)$ and calcium hydroxide $\left(\mathrm{Ca}(\mathrm{OH})_{2}\right)$ with a sodium phosphate $\left(\mathrm{Na}_{2} \mathrm{HPO}_{4}\right)$ solution. After setting and hardening, the cement is aged in water. High resolution structural and microstructure analyses are carried out to evaluate the stability of the CPC in water over a period of 150 days. The lattice parameters of the apatite crystal remain the same throughout the aging process. The size of apatite crystallites is not changed either; nevertheless, the shape of the particles changes from equiaxed to rod-like.

(C) 2007 Elsevier B.V. All rights reserved.
\end{abstract}

Keywords: Bone cement; Hydroxyapatite; Crystal structure; Morphology

\section{Introduction}

Calcium phosphate cement (CPC) has received wide interest for its potential use as bone cement [1-3]. Apart from the processing of the CPC, its biological affinity has been systematically investigated. Some CPCs have been proven to be bioactive and can be used as the fixation of the artificial joints (hip joints or knee joints) to bone stock.

The most attractive property of CPC is its ability to transform into an apatite structure at room temperature or human body temperature through a dissolution-precipitation mechanism [4-8]. Though the reaction takes place at room temperature; the reaction is very fast in the beginning 10 to $60 \mathrm{~min}$ [9-13]. After setting, the hardened CPC is inserted into a biological environment. The longterm stability of the CPC during aging in water is essential for its applications. Since the structure and morphology of the apatite particles affect the mechanical properties of CPC $[8,14,15]$, the long-term structure and microstructure stability during aging in water is thus of interest.

Dicalcium phosphate anhydrous (DCPA; $\mathrm{CaHPO}_{4}$ ) is frequently used as the starting material for bone cement. As a cement liquid is added into the powder mixtures of DCPA and $\mathrm{Ca}(\mathrm{OH})_{2}$, a bone cement is formed $[4,9,11,13,16,17]$. Hydroxyapatite (HAp; $\left.\mathrm{Ca}_{10}\left(\mathrm{PO}_{4}\right)_{6}(\mathrm{OH})_{2}\right)$ is the major product of the reaction. The

\footnotetext{
* Corresponding author. Tel.: +886 2 23659800; fax: +886 223634562 .
}

E-mail address: tuan@ccms.ntu.edu.tw (W.-H. Tuan). resulting HAp particles are in nanometer size range, it thus imposes challenges on the phase and morphology analyses. Though the structure and morphology of HAp particles have been characterized carefully by many groups [13-17], the long-term structure stability of HAp crystals has received relatively little attention. In the present study, the structure and morphology stabilities of the bone cement in water over a period of 150 days are investigated through high resolution XRD and SEM analyses.

\section{Experimental}

In the present study, dicalcium phosphate anhydrous (DCPA; $\mathrm{CaHPO}_{4}, 15-20 \mu \mathrm{m}$, Acros Organics Co., USA) and calcium hydroxide $\left(\mathrm{Ca}(\mathrm{OH})_{2}, 5-7 \mu \mathrm{m}\right.$, Acros Organics Co., USA) were used as the starting materials. These two powders were mixed thoroughly in an attritor (Union Process Co., Ohio, USA) in alcohol (purity 99.5\%) at a rotation speed of $500 \mathrm{rpm}$ for $6 \mathrm{~h}$. The ratio of the starting materials was adjusted to yield a $\mathrm{Ca} / \mathrm{P}$ ratio of 1.67 , the ratio for the stoichiometric hydroxyapatite $\left(\mathrm{Ca}_{10}\left(\mathrm{PO}_{4}\right)_{6}(\mathrm{OH})_{2}\right)$. The slurry was dried at $100{ }^{\circ} \mathrm{C}$ and screened to pass through a plastic sieve of $\# 150$. The final particle size of the powder mixtures was $1-3 \mu \mathrm{m}$.

Bone cement was prepared by mixing the powder mixtures with a cement liquid, $1.0 \mathrm{M} \mathrm{Na}_{2} \mathrm{HPO}_{4}$ solution, in a mortar and pestle. The liquid/powder weight ratio was 0.5 . The cement was then squeezed into a stainless mold to form cylindrical discs under an external pressure of $3 \mathrm{MPa}$. The discs were left at room 
temperature for $24 \mathrm{~h}$, then soaked in distilled water at $37^{\circ} \mathrm{C}$ for various soaking times from $0.5 \mathrm{~h}$ to $3600 \mathrm{~h}$. The $\mathrm{pH}$ value of the water bath was also monitored.

The crystal structure of CPC was characterized with a synchrotron X-ray source; these synchrotron experiments were performed at wiggler beamline BL-17B1 in the National Synchrotron Radiation Research Center (NSRRC), Hsinchu, Taiwan. Incident X-rays were focused vertically with a mirror and made monochromatic to an energy of $8 \mathrm{keV}$ with a $\mathrm{Si}$ (111) double-crystal monochromator; the sagittal bend of the second crystal focused the X-rays in the horizontal direction. With two pairs of slits between the sample and the detector, the typical scattering vector resolution in the vertical scattering plane was set to $\sim 5 \times 10^{-3} \mathrm{~nm}^{-1}$ in these experiments. The scattering angle $(2 \theta)$ varied from 25 to $45^{\circ}$. The lattice spacing, $d$, of each plane was determined by using the following equation $[13,18]$ :

$d=\frac{1}{\sqrt{\frac{4}{3 a^{2}}\left(h^{2}+k^{2}+h k\right)+\frac{l^{2}}{c^{2}}}}$

The crystal size was determined by measuring the width at half the maximum intensity and calculated with the Scherrer's equation $[16,18]$ as

$G=\frac{K \lambda}{B \cos \theta}$

In the above equation, $G$ is the average diameter of crystallites, $K$ the shape factor (a value of 0.9 was used), $B$ the width of the

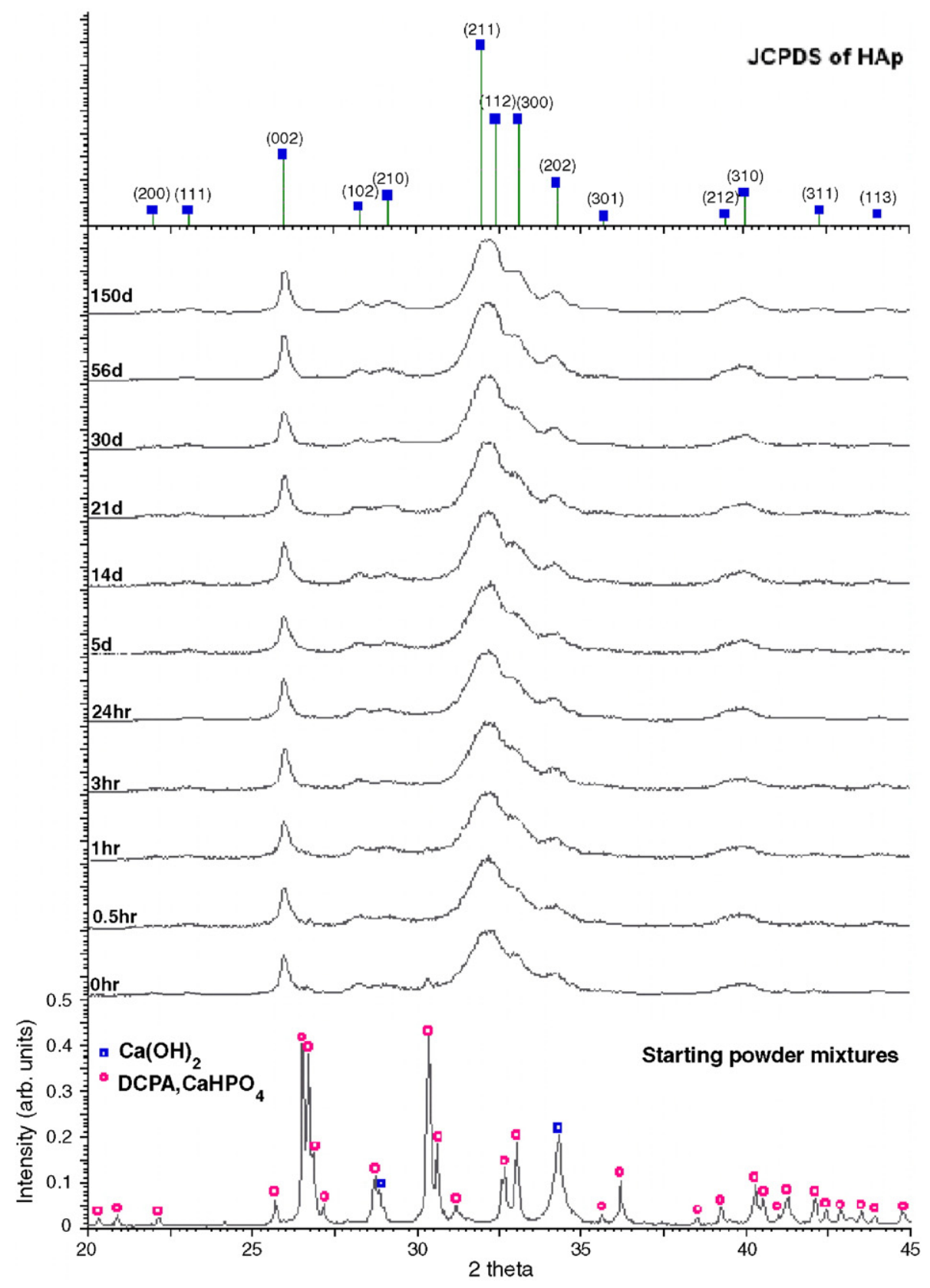

Fig. 1. XRD patterns of $\mathrm{CPC}$ after incubation in water for various times. The pattern for the starting $\mathrm{DCPA} / \mathrm{Ca}(\mathrm{OH})_{2}$ powder mixture is also shown. 
(002) peak at the half of its maximum height, $\lambda$ the wavelength of used X-rays, and $\theta$ the Bragg's diffraction angle.

The microstructure evolution during incubation was examined by using a high-resolution field-emission scanning electron microscopy (FE-SEM, model 1530, Leo Electron Microscopy Ltd., UK) and transmission electron microscopy (TEM, Jeol Co., Japan).

\section{Results}

Fig. 1 shows the XRD patterns obtained from the high resolution X-ray scattering analysis. The pattern for the starting powder mixtures of $\mathrm{DCPA} / \mathrm{Ca}(\mathrm{OH})_{2}$ is also shown for comparison. Fig. 2 shows the $\mathrm{pH}$ values of the water bath during incubation. The $\mathrm{pH}$ value drops rapidly after 24 h. Fig. 3 shows the lattice spacing of (002) plane as a function of incubation time. The lattice parameter remains the same throughout the incubation. The size of the HAp crystals is also estimated by measuring the width of (002) peak. Fig. 3 demonstrates that the size of the HAp crystals is around $20.6 \mathrm{~nm}$ throughout the incubation.

Fig. 4 shows the morphology of the apatite particles after the incubation for various times. The morphology of the starting powder mixtures is also shown for comparison, see Fig. 4(a). The large particles as identified by the energy dispersive X-ray (EDX) and electron-probe microanalysis (EPMA) analyses are DCPA particles. The fine particles on the surface of DCPA particles are $\mathrm{Ca}(\mathrm{OH})_{2}$ particles. The fine $\mathrm{Ca}(\mathrm{OH})_{2}$ particles stick to the surface of large DCPA particles after mixing. Though the DCPA particles are one order of magnitude larger than the $\mathrm{Ca}$ $(\mathrm{OH})_{2}$ particles; the two starting powders are mixed uniformly after using the milling and drying steps adopted in the present study. Typical TEM micrographs of the HAp particles are shown in Fig. 5. The figure shows that the nano-HAp particles are present as clusters of many fine HAp particles.

\section{Discussion}

The X-ray scattering analysis indicates that the HAp phase is found before the aging process. Apart from HAp phase, a small

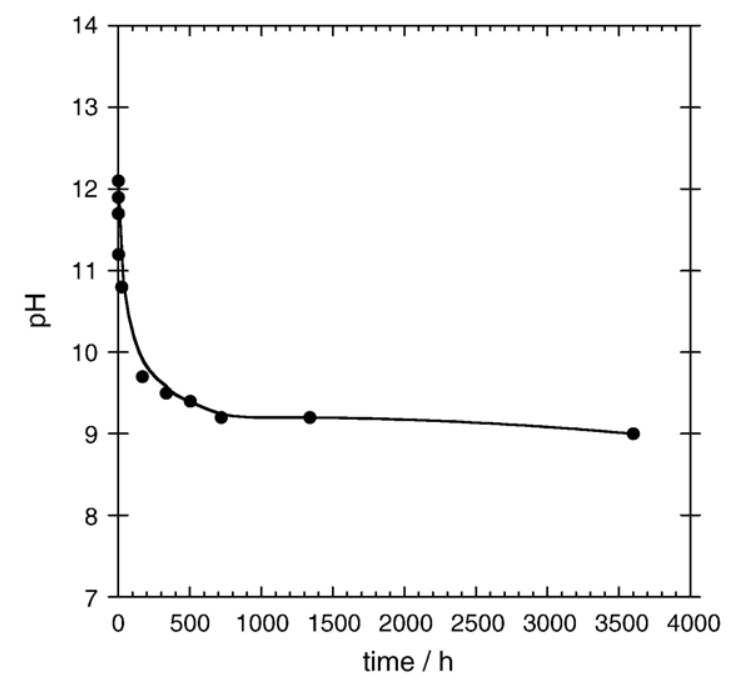

Fig. 2. $\mathrm{pH}$ value of water bath as a function of incubation time.

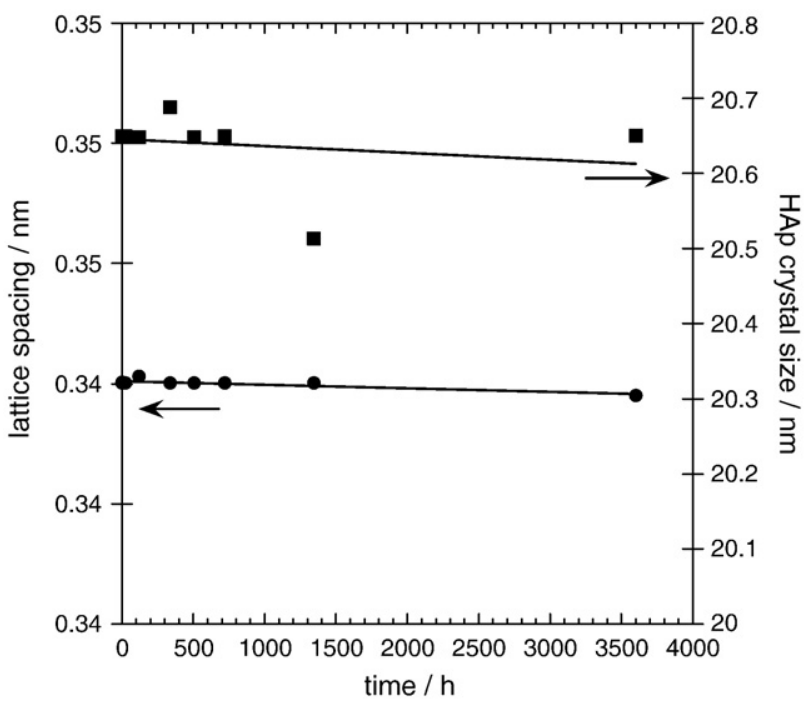

Fig. 3. Lattice spacing of (002) planes and the size of HAp crystallites as a function of incubation time.

amount of DCPA is found in the beginning $24 \mathrm{~h}$ in water. It suggests that the following chemical reaction has taken place before the incubation

$6 \mathrm{CaHPO}_{4}+4 \mathrm{Ca}(\mathrm{OH})_{2} \stackrel{\mathrm{Na}_{2} \mathrm{HPO}_{4(\text { (aq) }}}{\longrightarrow} \mathrm{Ca}_{10}\left(\mathrm{PO}_{4}\right)(\mathrm{OH})_{2}+6 \mathrm{H}_{2} \mathrm{O}$

After $24 \mathrm{~h}$ in water, the DCPA is no longer found and the HAp phase the only phase in the CPC. The HAp phase is stable within the time period of $3600 \mathrm{~h}$ (150 days). In the beginning of incubation, the $\mathrm{pH}$ is higher than the equilibrium $\mathrm{pH}$ value $(\sim 10)$ for the HAp in water [19]. It thus suggests that the reaction, Eq. (3), is not finished in the first $24 \mathrm{~h}$. It is also confirmed by the XRD analysis that residual DCPA is found only in the beginning of incubation.

Once the cement liquid is added, the HAp crystals start to form. The reaction is continuous during the beginning $24 \mathrm{~h}$ in air. The reaction (3) is nearly finished before the specimens are submerged in water. In the beginning of the aging, the HAp particles are equiaxed, then transform to rod-like particles after $24 \mathrm{~h}$ in water (see Fig. 4). The size of the apatite particles is around $100 \mathrm{~nm}$ long and $20 \mathrm{~nm}$ wide at the incubation time of $24 \mathrm{~h}$. As incubation time increases to $3600 \mathrm{~h}$, the apatite particles grow to around $200 \mathrm{~nm}$ long and $50 \mathrm{~nm}$ wide. The aspect ratio of the HAp rod is more or less the same once the rod is formed, see Fig. 4(c) and (d).

Despite the growth of the particles during incubation; highresolution structure analysis, Figs. 1 and 3, indicates that the crystal size of HAp is the same throughout the incubation. The microstructure observation thus raises the question on the contribution of dissolution of precipitation to the morphology evolution during the aging process. The change of crystal size takes place only in the very beginning of incubation. Within this time period, the chemical reaction is not complete, as evidenced by the presence of DCPA (see Fig. 1) and high $\mathrm{pH}$ value (see 
(a)

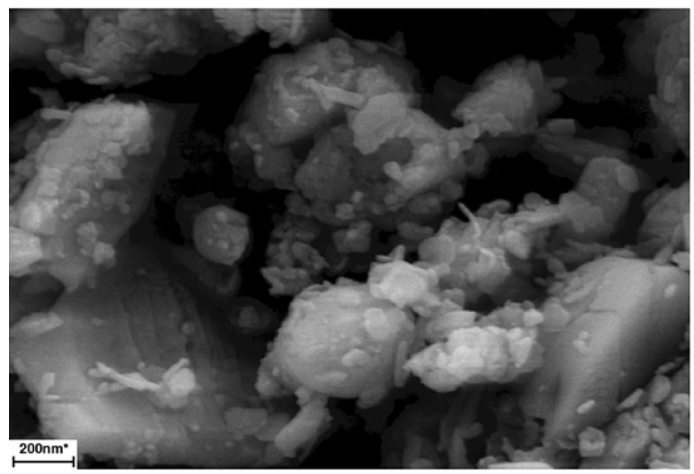

(c)

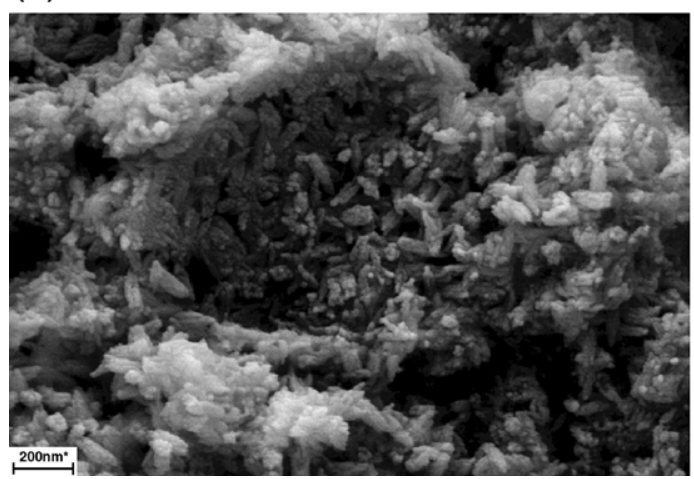

(b)

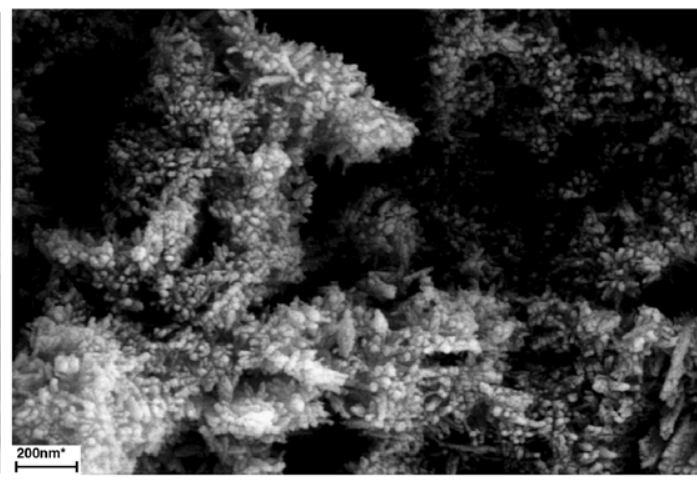

(d)

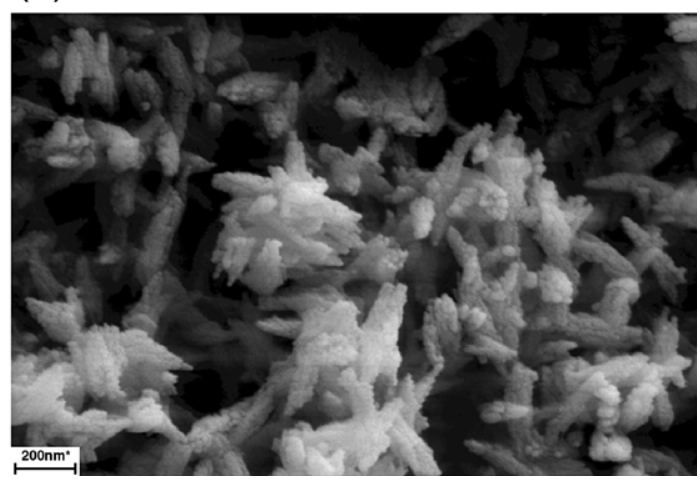

Fig. 4. Morphology of (a) starting DCPA/Ca(OH) 2 powder mixture and the CPC particles after incubation for (b) $0 \mathrm{~h}$, (c) $24 \mathrm{~h}$ and (d) $3600 \mathrm{~h}$.

Fig. 2). Once the reaction is finished, the $\mathrm{pH}$ value drops quickly. The dissolution rate also decreases, as well as the precipitation rate. The high-resolution XRD analysis indicates that the size of HAp crystal remains the same during aging in water for a long period of time (see Fig. 3). The high resolution SEM observation suggests that the shape of the HAp particles changed from equiaxed shape to rod-like shape (see Fig. 4). However, the TEM analysis gives the evidence that the HAp particle is more or less equiaxed (see Fig. 5) after aging in water. The HAp crystals are likely to stick together by capillary force or Van der Waals force due to the presence of the water. The HAp particles can thus change their shape without changing the crystal size.

\section{Conclusions}

In the present study, the stability of HAp particles in CPC during incubation in water is investigated by applying highresolution structure and microstructure analyses. The HAp crystallite remains stable in terms of lattice parameter and crystallite size throughout the aging process. The shape of the HAp particles changes from particulate to rod-like in the beginning of aging, then the length of the rod increases slowly from $100 \mathrm{~nm}$ to $200 \mathrm{~nm}$ within $3600 \mathrm{~h}$.

The particle size of the starting powder is smaller than $1 \mu \mathrm{m}$, indicating that the attrition milling is also an effective technique to reduce the size of the DCPA and $\mathrm{Ca}(\mathrm{OH})_{2}$ powders. The smaller the size of the starting particles, the faster the reaction rate. The reaction between the DCPA and $\mathrm{Ca}(\mathrm{OH})_{2}$ prepared in the present study is thus finished within $24 \mathrm{~h}$ in water.

\section{Acknowledgements}

The present study was supported by the National Science Council of Taiwan through the contract number of NSC9422216-E-002-014.

\section{References}

[1] W.E. Brown, L.C. Chow, J. Dent. Res. 63 (1983) 672.

[2] W.E. Brown, L.C. Chow, in: P.W. Brow (Ed.), Cement Research Progress, American Ceramic Society, Westerville, Ohio, 1986, p. 352.

[3] P.D. Costantino, C.D. Friedman, K. Jones, L.C. Chow, G.A. Sisson, Plast. Reconstr. Surg. 90 (1992) 174.

[4] S.E. Gruninger, C. Siew, L.C. Chow, A.O. Brown, W.E. Brown, J. Dent. Res. 63 (1984) 200.

[5] Y. Fuhkase, E.D. Eanes, S. Takag, L.C. Chow, W.E. Brown, J. Dent. Res. 69 (1990) 1852.

[6] K. Ishikawa, E.D. Eanes, J. Dent. Res. 72 (1993) 474

[7] A.A. Chohayeb, L.C. Chow, P. Tsaknis, J. Endodont 13 (1987) 384.

[8] C. Liu, W. Shen, Y. Gu, L. Hu, J. Biomed. Mater. Res. 35 (1997) 75.

[9] Y. Fukase, E.D. Eanes, S. Takag, L.C. Chow, W.E. Brown, J. Dent. Res. 69 (1990) 1852.

[10] E.C. Moreno, T.M. Gregory, W.E. Brown, J. Res. Natl. Bur. Stand. (U. S.) 72A (1968) 773 .

[11] A.C. Tas, S.B. Bhaduri, J. Am. Ceram. Soc. 87 (2004) 2195.

[12] M.T. Fulmer, P.W. Brown, J. Mater. Sci., Mater. Med. 9 (1998) 197. 
(a)

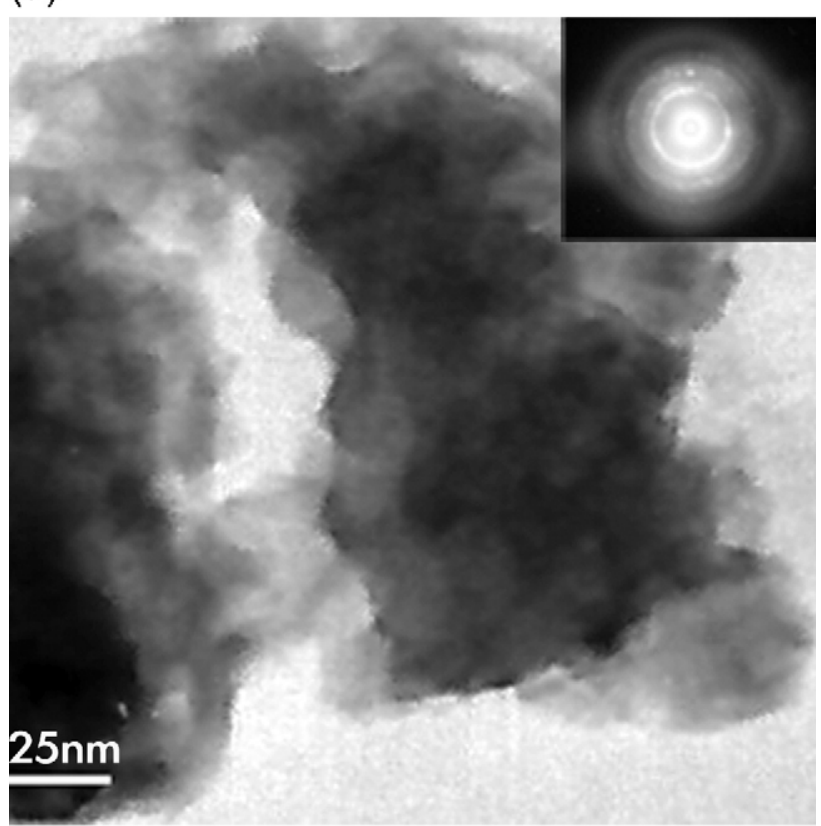

(b)

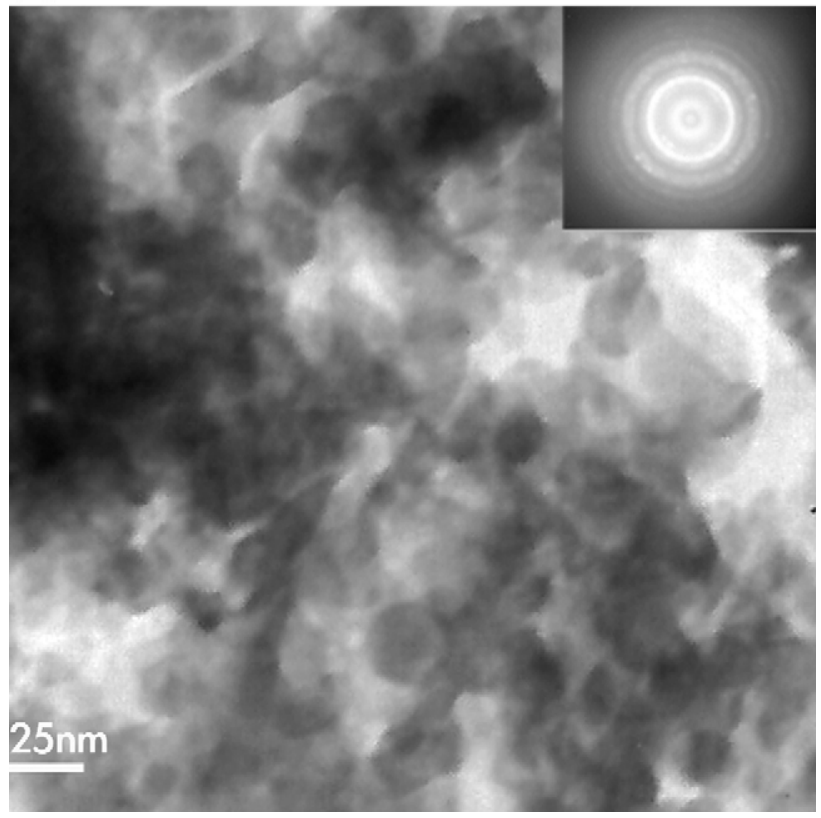

Fig. 5. TEM micrographs of CPC particles after incubation for (a) $24 \mathrm{~h}$ and (b) $3600 \mathrm{~h}$.
[13] D. Eichert, M. Salome, M. Banu, J. Susini, C. Rey, Spectrochim. Acta, Part B: Atom. Spectrosc. 60 (2005) 850.

[14] S. Takagi, L.C. Chow, J. Mater. Sci., Mater. Med. 12 (2001) 135.

[15] J.E. Barralet, K.J. Lilley, L.M. Grover, D.F. Farrar, C. Ansell, U. Gbureck, J. Mater. Sci., Mater. Med. 15 (2004) 407.

[16] A. Bezjak, I. Jelenic, Cem. Concr. Res. 10 (1980) 553.

[17] S. Jinawath, D. Pongkao, M. Yoshimura, J. Mater. Sci., Mater. Med. 13 (2002) 491.

[18] X. Lu, Y. Leng, Biomaterials 26 (2005) 1097.

[19] E.F. Burguera, F. Guitian, L.C. Chow, J. Biomed. Mater. Res. 71A (2004) 275 